\title{
Voice Quality Planning for NGN including Mobile Networks
}

\author{
Ivan Pravda ${ }^{1}$, Jiri Vodrazka ${ }^{1}$, \\ ${ }^{1}$ Czech Technical University of Prague, Faculty of Electrical Engineering, \\ Technicka 2, 16627 Prague 6, Czech Republic \\ pravdai@fel.cvut.cz, vodrazka@fel.cvut.cz
}

\begin{abstract}
The plan of transmission parameters or the network plan was created for Czech Republic in 2005 and this plan has had key effect on traffic in the telecommunication networks providing public telephone service, including mobile networks, NGN networks based on IP protocol and private networks connected to public telephone network. This paper describes practical effects of aforesaid plan on some typical situations in the network. Related research projects of the Department of Telecommunications Engineering, Faculty of Electrical Engineering, CTU in Prague are presented here, such as tandem arrangement of codecs and non-intrusive monitoring of voice quality.
\end{abstract}

Keywords: Voice quality, Transmission plan, E-model, R-factor

\section{Introduction}

The global telephone network transmission environment has rapidly changed. The IP based Next generation networks are build, the networks providers are interconnected and the private networks are connected to the public networks. Today, dominant part of telephone traffic uses the mobile and other wireless networks. The traditional transmission planning methodologies and documents are no longer flexible enough to account for all these new factors. For modern transmission planning, the following issues have to be considered:

- Multinational networks (especially private networks) become common and require planning which takes into account regional differences in loss plan requirements and inter-network transmission plans.

- Due to the liberalization of the telecommunication markets there are no longer laid down ranges of values for transmission parameters by regulation.

- The changing scenario in the public network operator domain is impacting transmission performance.

- The network plan should be applicable to the use of new technology within the networks under consideration, including cordless or mobile sections and transmission of packet voice (VoIP).

New public telephone network plan of the transmission parameters for Czech Republic was published by regulator - CTU - in 2005 [1].

Please use the following format when citing this chapter:

Pravda, I., Vodrazka, J., 2007, in IFIP International Federation for Information Processing, Volume 245, Personal

Wireless Communications, eds. Simak, B., Bestak, R., Kozowska, E., (Boston: Springer), pp. 376-383. 
The plan was created in special workgroup constituted at The Association of Public Telecommunication Network Operators in Czech Republic (APVTS) with both authors of this article actively participating.

\section{Basic Parameters of Network Plan for the Czech Republic}

The plan of transmission parameters defines a reference configuration with two interconnected networks $\mathrm{A}$ and $\mathrm{B}$, or with third possible network $\mathrm{C}$ connecting both networks A and B (see fig. 1). The parameters are defined between acoustic interfaces of subscribers, eventually between access points of these networks. As terminal equipment can be used a classic analog or ISDN telephone, a wireless telephone (DECT), a mobile terminal (GSM, UMTS), an IP telephone, a Wi-Fi phone, etc. The plan includes possible private automatic branch exchanges (PABX) and private networks (PN) of companies or institutions.

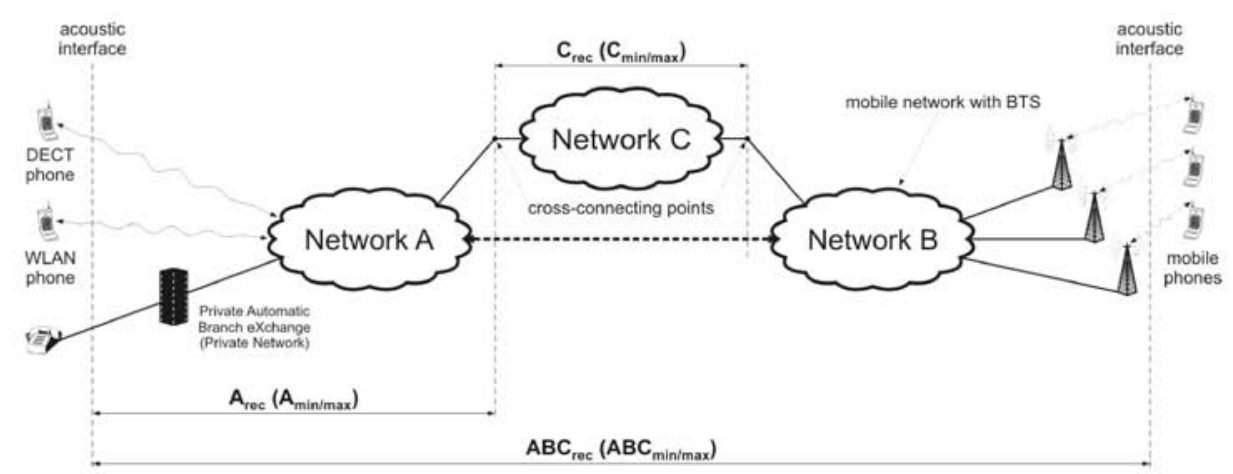

Fig. 1. The reference network configuration for telephone network plan of the transmission parameters for the Czech Republic

\subsection{Recommended Values and Limits}

Next overview indicates monitored parameters and their recommended and limited values. Firstly see tab. 1 for total values among acoustic interfaces of the network, marked in general ABC (via all three subnetworks). Key parameter is compliance of total R-factor higher than 50, that corresponds with total impairment factor equal to 50 (lowered by advantage factor A: the relevant value is 10 in mobile networks is, and 5 in connection with cordless terminals).

Key effect has delay in NGN networks (low value of delay close to zero ( $\sim 0 \mathrm{~ms}$ ), is assumed in classic networks, in practice it limits to ones ms). A delay between terminal points of network and access points is required to be in compliance with quality parameters of class 0 , in the networks with packet switching according to the Recommendation ITU-T Y.1541 [14]. It is defined by IP packet delay (IPTD) at 
maximum of $100 \mathrm{~ms}$ and IP delay variation (IPDV) at maximum of $50 \mathrm{~ms}$. Besides inherent delay close to session, echoes in combination with unbalanced hybrid and with acoustic coupling between earphone and microphone have very negative effect. Networks, where equally high Talker Echo Loudness Rating (TELR) at the receiving side with regard to delay of voice signal isn't guaranteed, have to be provided by suppressors of echo. Next tables 2 and 3 contain recommended and limit values for subnetworks A or B (tab. 4) and intermediate network C (tab. 5). Key parameter is compliance of particular impairment factor.

Table 1. Recommended and limit values between terminate points of public telephone network in the Czech Republic.

\begin{tabular}{|c|c|c|c|c|c|}
\hline & Parameter & & $\mathbf{A B C}_{\text {rec }}$ & $\mathbf{A B C}_{\min }$ & $\mathbf{A} \mathbf{B C}_{\max }$ \\
\hline $\mathrm{A}$ & Advantage Factor & - & $0 ; 5 ; 10$ & - & - \\
\hline $\mathrm{qdu}$ & Quantization Distortion Units & - & 1 to 8 & 1 & 14 \\
\hline $\mathbf{R}$ & Rating Factor & - & $\mathbf{5 0}$ to $\mathbf{1 0 0}$ & $\mathbf{5 0}$ & $\mathbf{1 0 0}$ \\
\hline $\mathrm{I}_{\text {tot }}-\mathrm{A}$ & Impairment Factor & - & 0 to 50 & 0 & 50 \\
\hline OLR & Overall Loudness Rating & {$[\mathrm{dB}]$} & 0 to 18 & -6 & 29,5 \\
\hline $\mathrm{T}_{\mathrm{a}}$ & Absolute Delay & {$[\mathrm{ms}]$} & $\sim 0$ to 200 & $\sim 0$ & 500 \\
\hline TELR & Talker Echo Loudness Rating & {$[\mathrm{dB}]$} & \multicolumn{2}{|c|}{ Define by graph dependence on Ta } \\
\hline
\end{tabular}

Table 2. Recommended and limit values for terminate network A or B in the Czech Republic.

\begin{tabular}{|c|c|c|c|c|c|}
\hline & Parameter & & $\mathbf{A}_{\text {rec }} \mathbf{B}_{\text {rec }}$ & $\mathbf{A}_{\min } \mathbf{B}_{\min }$ & $\mathbf{A}_{\max } \mathbf{B}_{\max }$ \\
\hline $\mathrm{A}$ & Advantage Factor & - & $0 ; 5 ; 10$ & - & - \\
\hline $\mathrm{qdu}$ & Quantization Distortion Units & - & 1 to 4 & 1 & 5 \\
\hline $\mathbf{I}_{\text {tot }}-\mathbf{A}$ & Impairment Factor & - & $\mathbf{0}$ to $\mathbf{1 8}$ & $\mathbf{0}$ & $\mathbf{1 8}$ \\
\hline $\mathrm{RLR}$ & Receive Loudness Rating & {$[\mathrm{dB}]$} & $-1,75$ to 7,25 & $-4,25$ & 13 \\
\hline SLR & Send Loudness Rating & {$[\mathrm{dB}]$} & 1,75 to 10,75 & $-1,25$ & 16,5 \\
\hline $\mathrm{T}_{\mathrm{a}}$ & Absolute Delay & {$[\mathrm{ms}]$} & $\sim 0$ to 100 & $\sim 0$ & 200 \\
\hline TELR & Talker Echo Loudness Rating & {$[\mathrm{dB}]$} & \multicolumn{5}{|c|}{ Define by graph dependence on Ta } \\
\hline
\end{tabular}

Table 3. Recommended and limit values for transit network $\mathrm{C}$ in the Czech Republic.

\begin{tabular}{|c|c|c|c|c|c|}
\hline & Parameter & & $\mathbf{C}_{\text {rec }}$ & $\mathbf{C}_{\min }$ & $\mathbf{C}_{\max }$ \\
\hline qdu & Quantization Distortion Units & - & 0 & 0 & 4 \\
\hline $\mathbf{I}_{\text {tot }}-\mathbf{A}$ & Impairment Factor & - & $\mathbf{0}$ to $\mathbf{1 4}$ & $\mathbf{0}$ & $\mathbf{1 4}$ \\
\hline $\mathrm{RLR}$ & Receive Loudness Rating & {$[\mathrm{dB}]$} & 0 & 0 & 0 \\
\hline SLR & Send Loudness Rating & {$[\mathrm{dB}]$} & 0 & 0 & 0 \\
\hline $\mathrm{T}_{\mathrm{a}}$ & Absolute Delay & {$[\mathrm{ms}]$} & $\sim 0$ & $\sim 0$ & 100 \\
\hline
\end{tabular}




\section{$2.2 \quad$ Using of E-model}

The public telephone network plan of the transmission parameters for the Czech Republic uses the E-model for complex quality view on the network. The guidelines and planning examples of Recommendation G.108 [12] are based on the utilization of the E-Model as described in Recommendation G.107 [11]. The intent of this Recommendation is to demonstrate how the E-Model can be used in end-to-end transmission planning for a wide range of local, national, multinational and transcontinental networks. The basic equation for the Rating from Recommendation G.107 is modified to next equations:

$$
R=100-I_{t o t}+A
$$

where $A$ is Advantage Factor and $I_{\text {tot }}$ is total Impairment Factor:

$$
I_{t o t}=I_{o}+I_{q}+I_{d t e}+I_{d d}+I_{\text {eeff }}
$$

$I_{o}$ - Impairment Factor - noise and loudness rating

$I_{q}$ - Impairment Factor - quantizing distortion

$I_{d t e}$ - Impairment Factor - talker echo

$I_{d d}$ - Impairment Caused by too-long Absolute Delay

$I_{\text {eeff }}$ - Effective Equipment Impairment Factor

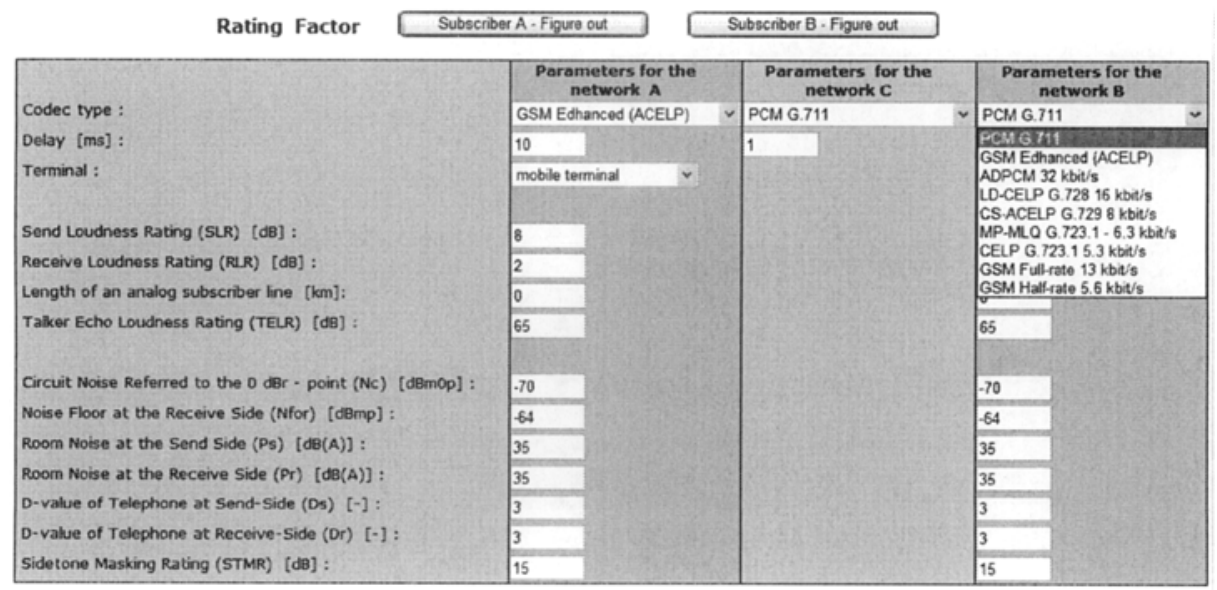

Fig. 2. The input page of the complex R-factor calculation tool for interconnected networks A, B, C (http://matlab.feld.cvut.cz/en) 


\subsection{Calculation Tool}

The Prague Department of Telecommunication Technology co-operated with the APVTS (Public Telecommunication Networks Provider Association) on the Public telephone network plan of the transmission parameters for the Czech Republic and produced the web application for E-model parameters calculation, which was used for optimization of basic transmission parameters and default constants of model. The basic tool calculates the R-factor from the input networks parameters. The second tool calculates the R-factor for the parameters of three co-operating networks. The input page of the complex R-factor calculation tool for interconnected networks A, B, C is shown on the Fig. 2. The calculation tools were programmed for the MATLAB Server and they are accessible on the web site http://matlab.feld.cvut.cz/en [2], [3].

\section{Tandem Concatenation of Codec}

Assorted combinations of codecs can occur in extreme case in the networks. For example - mobile subscriber uses codec FR (network A) through network $C$ based on PCM and call is terminated in private network B based on codec according to the Recommendation ITU-T G.729. This tandem concatenation of more codecs isn't recommended, within codec PCM (ITU-T G.711) used in combination with any low speed codec. According to E-model the total impairment factor should add up all impairment factors of concatenated codecs. Computation model was modified in our simulation program on the basis of practical experience and results of simulations.

Table 4. Simulated values of impairment factor for single codec used in mobile networks.

\begin{tabular}{|l|c|}
\hline $\begin{array}{l}\text { Type of } \\
\text { Codec }\end{array}$ & $\begin{array}{c}\text { Equipment } \\
\text { Impairment Factor }\end{array}$ \\
\hline PCM & 0 \\
\hline HR & 29.89 \\
\hline FR & 10.12 \\
\hline EFR & 2.17 \\
\hline AMR 4,75 & 30.75 \\
\hline EFR & 2.17 \\
\hline
\end{tabular}

PCM - Pulse Code Modulation - $64 \mathrm{~kb} / \mathrm{s}$

HR - GSM Half Rate - $5,6 \mathrm{~kb} / \mathrm{s}$

FR - GSM Full Rate - $13 \mathrm{~kb} / \mathrm{s}$

EFR - GSM Enhanced Full Rate - 12,2 kb/s

AMR - GSM Adaptive Multi-Rate - from 1,85 to $12,20 \mathrm{~kb} / \mathrm{s}$

Firstly the Table 4 shows values of impairment factor, which we obtain for one codec, then the Table 5 shows values for tandem concatenation of assorted combinations of codecs. It's proved that utilization of PCM codec practically doesn't lead to impairment of resulting quality. It's impossible to say that combination of assorted 
codecs embodies impairment accordant to addition of particular impairment factors. Results are fundamentally better in general.

Table 5. Simulated values of impairment factor for tandem concatenation of codec.

\begin{tabular}{|l|c|}
\hline $\begin{array}{l}\text { Combination } \\
\text { of Codec }\end{array}$ & $\begin{array}{c}\text { Equipment } \\
\text { Impairment Factor }\end{array}$ \\
\hline HR - HR & 38.91 \\
\hline FR - FR & 15.12 \\
\hline FR - EFR & 14.86 \\
\hline FR - HR & 30.92 \\
\hline FR - PCM & 11.69 \\
\hline EFR - EFR & 11.15 \\
\hline EFR - HR & 29.03 \\
\hline EFR - PCM & 2.95 \\
\hline AMR - AMR & 44.71 \\
\hline AMR - FR & 36.53 \\
\hline AMR - EFR & 36.23 \\
\hline AMR - HR & 41.73 \\
\hline AMR - PCM & 32.57 \\
\hline
\end{tabular}

\section{Conclusion}

The Prague Department of Telecommunication Technology participation on development of the public telephone network plan of the transmission parameters for the Czech Republic was very positively evaluated by CTU (Czech Telecommunication Union) and APVTS (Public Telecommunication Networks Provider Association). The finalization of the public telephone network plan of the transmission parameters allows the QoS control for the interconnected telecommunication networks including NGN in the Czech Republic.

It is evident, that transmission delay and utilization of low speed codecs are main limiting factors lowering quality of speech transfer in next generation networks. It's necessary to adjust network parameters so that the compliant value of $\mathrm{R}$-factor (the best is higher than 60) is reached, together with cooperation of different types of networks and interconnection with private networks. Quantity of network's delay is arbitrating for quality of call realized in only one network utilizing specific codec as well as type of used terminal, which specifies impairment factor A. Quality of call is good for delay up to $200 \mathrm{~ms}$, but only in connection with echo cancellation process. Quality of call is unsuitable for delay over $500 \mathrm{~ms}$ altogether.

The best quality is in connection with utilization of codec PCM G.711 in all networks, because this codec has minimal total impairment of speech quality. More advanced coding ACELP is recommended for mobile networks, because it reaches better results than classic codec RPE-LTP.

The tandem concatenation of more codecs isn't recommended, excepting PCM codec ITU-T G.711 used in combination with arbitrary low speed codec. The tandem concatenation of codec creates lower reduction of quality than direct addition of 
impairments factors in E-model. It results from practical experience and results of realized simulations.

The mobile terminals are better evaluated by users (advantage factor A) because of their perception of mobility as an advantage. But it's necessary to consider communication process between mobile terminal and fixed terminal, whose users do not feel this advantage. Also, lower quality tolerance is higher for lower costs per one call. There is indeed similar quality imbalance, because user paying standard tariff requires corresponding quality, used by him, regardless from what network the call is coming.

The plan of transmission parameters of private telephone networks represents important technical, but also legal document, which influences public telephone networks and private networks connected to public telephone network providers. This plan puts a pressure on providers to serve up sufficient quality of voice communication and to do more effective networks planning. Further more it's possible to use calculation according to E-model, eventually systematic measurement in the network by suitable measurement methods providing directly R-factor, eventually MOS parameter, from which the R-factor is easily re-counted.

The problems can naturally occur in case when provider wants to measure quality in the networks through non-intrusive method, e.g. continuous monitoring in real traffic. There are distinctive deviations between results of measurements realized by subjective evaluation of quality of speech in Czech language and results of measuring by $3 \mathrm{SQM}$ method. It seems that this method is only limitedly applicable for Czech language and it is necessary to adjust the psychoacoustic model according to real results.

Acknowledgment. This work has been supported by the Grant Agency of the Academy of Sciences of the Czech Republic under project 1ET300750402 and Czech Technical University's grant No. CTU0715013.

\section{References}

1. Transmission Plan for New Generation Telephone Networks. Czech Telecommunication Office. Prague 2005.

2. Vodrazka, J. - Jares, P. - Hubeny, T.: Rating Factor. Simulation program on-line: Matlab Server. http://matlab.feld.cvut.cz/en/

3. Vodrazka, J. -- Jares, P. - Hubeny, T.: Rating Factor for cooperative networks. Simulation program on-line: Matlab Server. http://matlab.feld.cvut.cz/en/

4. Vodrazka, J.: Transmission Plan for Public Telephone Services in NGN. In Proceedings ECSIP-M 2005. Bratislava: The Faculty of Electrical Engineering and Information Technology of the Slovak University, 2005, s. 354-357. ISBN 80-227-2257-X.

5. Chu, Wai C.: Speech coding algorithms, Foundation and Evolution of Standardized Coders. John Wiley \& Sons, Inc., Hoboken, New Jersey 2003.

6. Kuo Pei-Jeng - Omae Koji - Okajima Ichiro - Umeda Narumi: VoIP quality evaluation in Mobile wireless networks Advances in multimedia information processing. PCM 2002 IEEE Pacific Rim conference on multimedia No3, Hsinchu, 16-18 December 2002. vol. 2532, pp. 688-695, ISBN 3-540-00262-6 
7. Janssen, J. - De Vleeschauwer, D. - Buchli, M - Petit, G.: Assessing voice quality in packetbased telephony. IEEE Internet Computing. Vol. 6, no. 3, pp. 48-56. 2002

8. Rein, S. - Fitzek, F. H. P. - Reisslein, M.: Voice quality evaluation for wireless transmission with ROHC. Seventh IASTED International Conference on Internet and Multimedia Systems and Applications; Honolulu, USA; 13-15 Aug. 2003. pp. 461-466. 2003

9. Nemčík, M. - Levák, M.: An Objective Method for End-to-End Speech Quality Assessment Using PESQ Algorithm. In Digital Technologies 2006 - 3rd International Workshop [CDROM]. Žilina: University of Žilina, Fakulty of electrical engineering, 2006, vol. 1, ISBN 808070-637-9.

9. ITU-T Recommendation G.101 (1996), The transmission plan.

10. ITU-T Recommendation G.107 (1998), The E-Model, a computational model for use in transmission planning.

11. ITU-T Recommendation G.108 (1999), Application of the E-model: A planning guide.

12. ITU-T Recommendation G.109 (1999), Definition of categories of speech transmission quality.

13. ITU-T Recommendation Y.1541 (2006), Network performance objectives for IP-based services. 